\title{
Chlorophyll increases off the coasts of Japan after the 2011 tsunami using NASA/MODIS data
}

\author{
E. Sava, B. Edwards, and G. Cervone \\ GeoInformatics and Earth Observation Laboratory, Department of Geography and Institute for CyberScience \\ The Pennsylvania State University, University Park, PA 16802, USA \\ Correspondence to: G. Cervone (cervone@psu.edu)
}

Received: 25 March 2013 - Published in Nat. Hazards Earth Syst. Sci. Discuss.: 3 July 2013

Revised: 21 May 2014 - Accepted: 9 June 2014 - Published: 6 August 2014

\begin{abstract}
Large chlorophyll anomalies are observed after the 2011 Japanese tsunami using the NASA MODIS instrument onboard the TERRA and AQUA satellites. These anomalies are observed both along the eastern coast of Japan, where the tsunami wave hit with maximum force, and in the deep water surrounding the epicentral region. Although both satellites show agreeing spatio-temporal patterns, larger anomalies are detected using the AQUA satellite. A temporal analysis shows increased chlorophyll concentrations immediately after the tsunami, and higher values are observed for nearly one month before reversing to pre-tsunami levels.
\end{abstract}

\section{Introduction}

On 11 March 2011 at 05:46 UTC a massive $M_{\mathrm{w}}=9.0$ underwater earthquake occurred $70 \mathrm{~km}$ offshore the eastern coast of Japan. The location of the earthquake was triangulated by the United States Geological Survey (USGS) to $38.322^{\circ} \mathrm{N}$ $142.369^{\circ} \mathrm{E}$ and the hypocenter was computed to $32 \mathrm{~km}$ beneath the surface. The earthquake generated a tsunami that rapidly hit the eastern coast of Japan, and propagated across the Pacific Ocean to the western coast of the Americas. A tsunami warning was issued by NOAA affecting all countries with coastlines along the Pacific Ocean ${ }^{1}$.

Waves up to $40 \mathrm{~m}$ high were reported and coastal areas were flooded up to several kilometers inland. National Oceanographic and Atmospheric Agency (NOAA) models ${ }^{2}$ predicted waves higher than $30 \mathrm{~m}$ along the eastern coast

\footnotetext{
${ }^{1}$ http://ptwc.weather.gov/ (last access: 11 March 2011)

${ }^{2}$ http://nctr.pmel.noaa.gov/honshu20110311/ (last access: 11 March 2011)
}

of Japan and up to $6 \mathrm{~m}$ for the western coast of the United States. An alternative model from the University of California at Santa $\mathrm{Cruz}^{3}$ predicted even larger wave heights in certain areas. As a result of the flooding, thousands of people have been proclaimed dead or missing, with the damages estimated to be in the order of several billion USD. Recent results suggest that the tsunami also caused large chlorophyll blooms along the Japanese coast (Siswanto and Hashim, 2012; Sarangi, 2011).

Chlorophyll is the primary photosynthetic molecule and is the basis for marine life (Kirk, 1983). There are six primary classifications of chlorophyll contained in plants and organisms, labeled from a to f. (Nakagawara et al., 2007). Remote sensing instruments can be used to estimate chlorophyll type $a$ and $b$. Both types function as light-harvesting pigments found in plant life. However, chlorophyll $a$ is located in plant antenna complexes and reaction centers and acts as an electron carrier, while chlorophyll $b$ is a component and stabilizer of peripheral antenna complexes (Tanaka et al., 1998; Nakagawara et al., 2007).

Microscopic organisms called phytoplankton also contain chlorophyll, and are crucial for marine life as they form the beginning of the food chain for all ocean organisms. The ocean, especially along coastal regions, is full of phytoplankton, and variations in chlorophyll concentrations are good estimates of phytoplankton production (Prakash and Ramesh, 2007).

Chlorophyll allows plants to absorb energy from light. When light is absorbed, plants or phytoplankton convert water and carbon dioxide into oxygen and energy. Without the help of chlorophyll plants would be unable to survive.

\footnotetext{
${ }^{3}$ http://www.es.ucsc.edu/ ward/ (last access: 18 March 2011)
} 
Chlorophyll also plays a role in the global carbon cycle because phytoplankton blooms decrease light penetration through the water column and can depress marine growth and productivity (Boyer et al., 2009).

Chlorophyll increase is a phenomenon that occurs primarily along the coasts, and is driven by upwelling of the lower strata of the ocean towards the surface (Saito et al., 1998). Upwelling occurs when nutrient-rich water rises to the ocean surface from depths of over $50 \mathrm{~m}$ (Small and Menzies, 1981). Transportation of deep, cold, nutrient-rich water to the surface triggers high chlorophyll production. Areas of upwelling can increase phytoplankton growth, which contribute to the fisheries of the world (Rykaczewski and Checkley, 2008).

\subsection{Chlorophyll variation along the Japanese coast}

Along the Japanese coasts, large chlorophyll concentrations are present at depth (i.e., DCM: deep chlorophyll maximum), and as a result of upwelling of nutrients, large blooming can be observed at the surface (Cullen, 1982; Yamada et al., 2004). In this region, upwelling is driven primarily by three factors (Furuya et al., 1993; Takeoka et al., 1997; Kasai et al., 1997; Saito et al., 1998):

1. wind induced

2. tidal mixing

3. thermohaline circulation.

Wind-induced upwelling is caused by the displacement of water masses and their replacement with nutrient-rich water coming from deeper layers, like when a cross-shore pressure gradient supports an alongshore geostrophic wind (Sverdrup, 1938; Bakun et al., 2010). This wind drives surface water offshore, and cannot be replaced by waters moving horizontally along the coast. Therefore this water has to be replaced by the upwelling of subsurface waters (Bakun et al., 2010).

Tidal mixing upwelling is caused by currents. Along the coasts of Japan, tidal effects are very strong, exhibiting sea height differences of the order of a few meters. Such changes are predictable based on the phases of the moon.

Thermohaline circulation upwelling is caused by normal seasonal ocean currents. In Japan, surface latent heat flux (SLHF), which is directly proportional to the evaporation of water, is usually high away from the coast in blue waters. To compensate, thermohaline circulation has an in-flowing component at depth, to compensate for the out-flowing surface water. Therefore, when high SLHF values are observed, the resulting in-flow of water at depth causes upwelling, and increases the chlorophyll concentrations. Due to SLHF seasonal patterns, larger chlorophyll increases can be expected during summer.

Additionally, extreme events such as tropical storms or tsunamis can cause large levels of upwelling both along the coasts and in the deep ocean. Large chlorophyll blooms have been observed after major hurricanes, typhoons, and tsunamis (Gautam et al., 2005; Walker et al., 2005; Son et al., 2006; Singh et al., 2007; Sarangi, 2012).

In particular, Sarangi (2012) analyzed NASA AQUA satellite data for 2009, 2010 and 2011 from February 26 to March 29 . This paper expands the initial findings by analyzing data for the entire year, and by comparing anomalies observed along the coast of Japan and in deep water.

\subsection{Retrieving chlorophyll using remote sensing}

It is possible to derive chlorophyll concentration by analyzing spectral changes in the green and blue part of the spectrum.

Chlorophyll concentrations are derived from ocean color, and thus can be readily estimated using remote sensing sensors (e.g., Neville and Gower, 1977; Sathyendranath et al., 1989; Kiyofuji et al., 2006; Tan et al., 2007; Radiarta and Saitoh, 2008). Chlorophyll products are generated by analyzing spectral measurements in the blue and green parts of the spectrum, roughly corresponding to the phytoplankton absorption peak and minimum, respectively.

Most algorithms have been developed for deriving concentrations in deep water where the reflection from the bottom can be neglected (Cannizzaro and Carder, 2006). The MODIS algorithms used in this study attempt to compensate the usually higher values of chlorophyll concentrations in coastal regions (Miller and McKee, 2004).

Datt (1998) showed how chlorophyll $a$ absorbs energy primarily in the blue-violet (400-475 nm) and orange-red (590$650 \mathrm{~nm}$ ) parts of the electro magnetic (EM) spectrum, and reflects energy primarily in the green part of the EM spectrum. In contrast, chlorophyll $b$ absorbs energy primarily in the green $(510 \mathrm{~nm})$ part of the EM spectrum. Chlorophyll $b$ complements chlorophyll $a$ by increasing the absorbtion of energy in the green part of the EM spectrum. This article is entirely based on observations of chlorophyll $a$, which are simply referred to as chlorophyll.

Since the 1980s, numerous sensors, such as NASA SeaWiFS, MODIS, and ESA MERIS, have been built and launched to study the variation of chlorophyll concentrations (O'Reilly et al., 1998; Bezy et al., 2000; Dall'Olmo et al., 2005; Kiyofuji et al., 2006). Algorithms have been developed to effectively quantify the amount of chlorophyll, and have been validated with in situ observations and other remotely sensed data (Antoine et al., 2008).

Two major steps are required to derive chlorophyll pigment using reflected radiation. First, atmospheric correction must be carried out to remove artifacts introduced by chemicals and aerosols (O'Reilly et al., 2000). Then, an algorithm is applied to generate the chlorophyll concentration product (Letelier and Abbott, 1996; Campbell and Feng, 2005; Huot et al., 2005). A major limitation of ocean color remote sensing is the sensitivity to meteorological conditions, particularly clouds. In fact, in the presence of clouds, the chlorophyll algorithms return no data for any pixels where clouds 
are detected. To compensate, it is customary to average the values for 3 days, a week, or even a month, in order to generate products with comprehensive spatial coverage.

In order to study the consequences of the 2011 Japanese tsunami on ocean phytoplankton, a remote sensing analysis has been carried out using the MODIS instrument onboard the TERRA and AQUA satellites. The chlorophyll products used had a $4 \mathrm{~km}$ spatial resolution and 3-day and 8-day composite temporal resolution. The data for the entire 2011 year were used in order to cover the tsunami and post-tsunami time period. This study focuses on the week the tsunami occurred as well as the weeks before and after. For comparison purposes, additional 3 -day $9 \mathrm{~km}$ resolution data were used to quantify the distribution between the tsunami and nontsunami periods.

Although the TERRA and AQUA satellites carry identical MODIS instruments, they are on different orbital paths, and thus their measurements of chlorophyll are different because they estimate it at different times of the day, as explained in Sect. 2. Furthermore, by averaging the measurements of TERRA and AQUA, it is possible to reduce the amount of cloud pixels in the scene, and increase the spatial coverage of the available data.

The objective of this study is to investigate the effects of the 2011 Japanese tsunami on chlorophyll $a$ concentrations and the distribution before and after the event using data from MODIS-AQUA and TERRA satellites. Our hypothesis is that major events, such as hurricanes or tsunamis, cause large disturbances in ocean waters, which can result in the upwelling of nutrients, and thus, chlorophyll increases.

\section{MODIS chlorophyll data}

Satellite remote sensing observations from the NASA MODerate Resolution Imaging Spectroradiometer (MODIS) instrument can be used to derive chlorophyll. MODIS is a moderate resolution multi-spectral sensor currently flying on two NASA satellites, AQUA and TERRA. MODIS uses midand thermal-IR for measuring the emissivity of the surface. MODIS chlorophyll products are corrected for atmospheric disturbances. A description of the MODIS chlorophyll products and their comparison with in situ measurements is discussed by (Esaias et al., 1998; Carder et al., 2004).

The AQUA satellite was designed to observe the earth's water cycle. Its sun-synchronous polar orbit (south to north) passes over the Equator in the afternoon (13:30 p.m.), and it acquires data for nearly the entire earth each day. The TERRA satellite was designed to collect data relating to the earth's biogeochemical and energy systems. TERRA is also in a sun-synchronous orbit and crosses the Equator at approximately 10:30 a.m. local time.

This study is based on standard AQUA and TERRA MODIS Level 3, $4.63 \mathrm{~km}$ gridded 3-day and 8-day composite products, generated through surface emissions. The grid- ded data are generated by binning and averaging the nominal $1 \mathrm{~km}$ swath observations, yielding a $\approx 4 \mathrm{~km}$ gridded global data. The data were downloaded from the NASA OceanColor website $^{4}$ and were processed using the SeaDAS 6.1 software, available from the same location. The data are distributed in HDF-EOS format. The use of MODIS data is limited to cloud-free conditions. Since MODIS is installed on both the TERRA and AQUA satellites, four data points are available per day.

MODIS data can be freely obtained through direct broadcast, which requires an X-band antenna and its control equipment, or from the NASA MODIS website. The data are distributed in HDF5-EOS format.

\section{Analysis of tsunami waves}

The 2011 tsunami was of unprecedented strength and affected the largest portion of the eastern coast of Japan in recorded history. Chlorophyll increases were observed using satellite remote sensing data over a large area, extending from the shallow areas along the coast to the deep water hundreds of kilometers away.

\subsection{Analysis of tsunami waves along the coast}

The tsunami hit the coast of Japan within minutes of the initial earthquake and is responsible for the loss of thousands of lives as well as massive damages to properties and the environment. In shallow water, waves measured several tens of meters, and penetrated far inland. The eastern coast of Japan received the most damage due to the proximity to the epicenter. Table 1 shows the recorded wave heights in different locations along the eastern coast of Japan for four tsunamis that occurred in 1896, 1933, 1960 and 2011. The 2011 tsunami had among the highest wave heights ever recorded, and affected the largest portion of the eastern shoreline. The damage caused by the 2011 tsunami was mapped by the International Charter for Space and Major Disasters ${ }^{5}$ using highresolution satellite data. The maps show the areas most affected by the tsunami and provide a near-real-time assessment of the damages (Cervone and Manca, 2011). The wave heights reported in Table 1 and the maps from the charter were used to define the area along the coast (R1) used in these experiments.

\subsection{Analysis of tsunami wave in deep water}

In deep water, tsunami waves have a much smaller amplitude, which is a function of the water depth. The dynamics for chlorophyll increases differ from shallow regions, but are also related to tsunamis. The 2011 tsunami was observed by buoys of the Deep-ocean Assessment and Reporting of

\footnotetext{
${ }^{4}$ http://oceancolor.gsfc.nasa.gov/ (last access: 13 April 2011)

${ }^{5}$ http://www.disasterscharter.org (last access: 13 April 2011)
} 


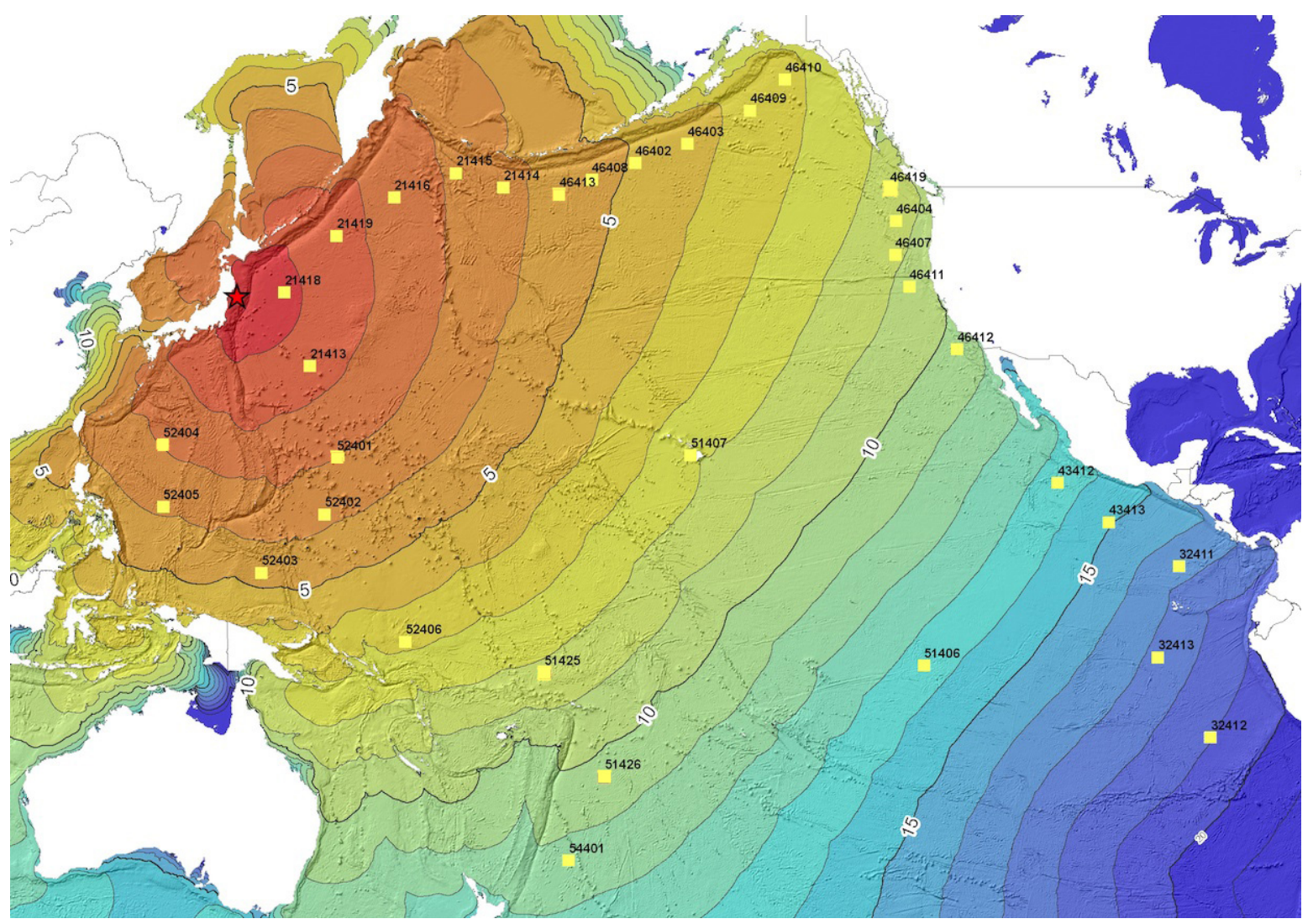

Figure 1. Tsunami wave travel time (in hours) and location of Pacific Ocean DART buoys used to quantify the wave height in deep ocean. The earthquake epicenter is indicated with a star. Image source: NOAA National Geophysical Data Center.

Table 1. Wave heights in meters recorded along the eastern coast of Japan for recorded tsunamis. Source: Japanese Society of Civil Engineers. Bold numbers indicate maximum wave heights recorded.

\begin{tabular}{lrrrr}
\hline Prefecture & 1896 & 1933 & 1960 & 2011 \\
\hline Hachinohe & 3.0 & 3.0 & 4.1 & $\mathbf{9 . 2}$ \\
Miyako & 18.3 & 13.6 & 5.8 & $\mathbf{3 5 . 2}$ \\
Ofunato & $\mathbf{3 8 . 2}$ & 8.9 & 5.5 & 30.1 \\
Ojika & 3.4 & 5.2 & 5.4 & $\mathbf{2 0 . 9}$ \\
Sendai & & 2.4 & 2.6 & $\mathbf{1 1 . 0}$ \\
Iwaki & & 1.2 & & $\mathbf{9 . 4}$ \\
Oarai & & & & $\mathbf{5 . 7}$ \\
\hline
\end{tabular}

Tsunamis (DART) tsunami warning system, scattered across the Pacific Ocean, which are designed to measure changes in wave height. Figure 1 shows the location of the buoys, and the tsunami wave travel time in hours computed by the Tsunami Travel Times (TTT) software ${ }^{6}$, which is provided by the NOAA National Geophysical Data Center. The epicenter of the earthquake is indicated with a star.

\footnotetext{
$6_{\text {www.ngdc.noaa.gov/hazard/tsu_travel_time_software.shtml }}$ (last access: 15 May 2011)
}

Table 2. ID and location of the DART buoys used to quantify the wave height in deep water.

\begin{tabular}{lll}
\hline Buoy ID & Latitude & Longitude \\
\hline 21418 & $38.718^{\circ} \mathrm{N}$ & $148.698^{\circ} \mathrm{E}$ \\
21413 & $30.528^{\circ} \mathrm{N}$ & $152.123^{\circ} \mathrm{E}$ \\
52402 & $11.882^{\circ} \mathrm{N}$ & $154.111^{\circ} \mathrm{E}$ \\
51407 & $19.62^{\circ} \mathrm{N}$ & $156.511^{\circ} \mathrm{W}$ \\
51406 & $8.48^{\circ} \mathrm{S}$ & $125.03^{\circ} \mathrm{W}$ \\
\hline
\end{tabular}

Figure 2 shows the water height in meters for 11 March 2011 measured by the DART buoys listed in Table 2. The data were filtered by performing a wavelet transformation. The data show an amplitude of $1.8 \mathrm{~m}$ for buoy 21418 and $1 \mathrm{~m}$ for buoy 21413 , the buoys closest to the epicenter, located $200 \mathrm{~km}$ west and $500 \mathrm{~km}$ southwest of the epicenter, respectively. The tsunami wave can be seen propagating across the Pacific, albeit with a much smaller magnitude.

The information in Fig. 2 was used to define the region in deep water (R2) used in the experiments. A region south of the epicentral area is defined, which extends almost all the way to buoy 21418 , where the highest tsunami waves in deep water were observed. 

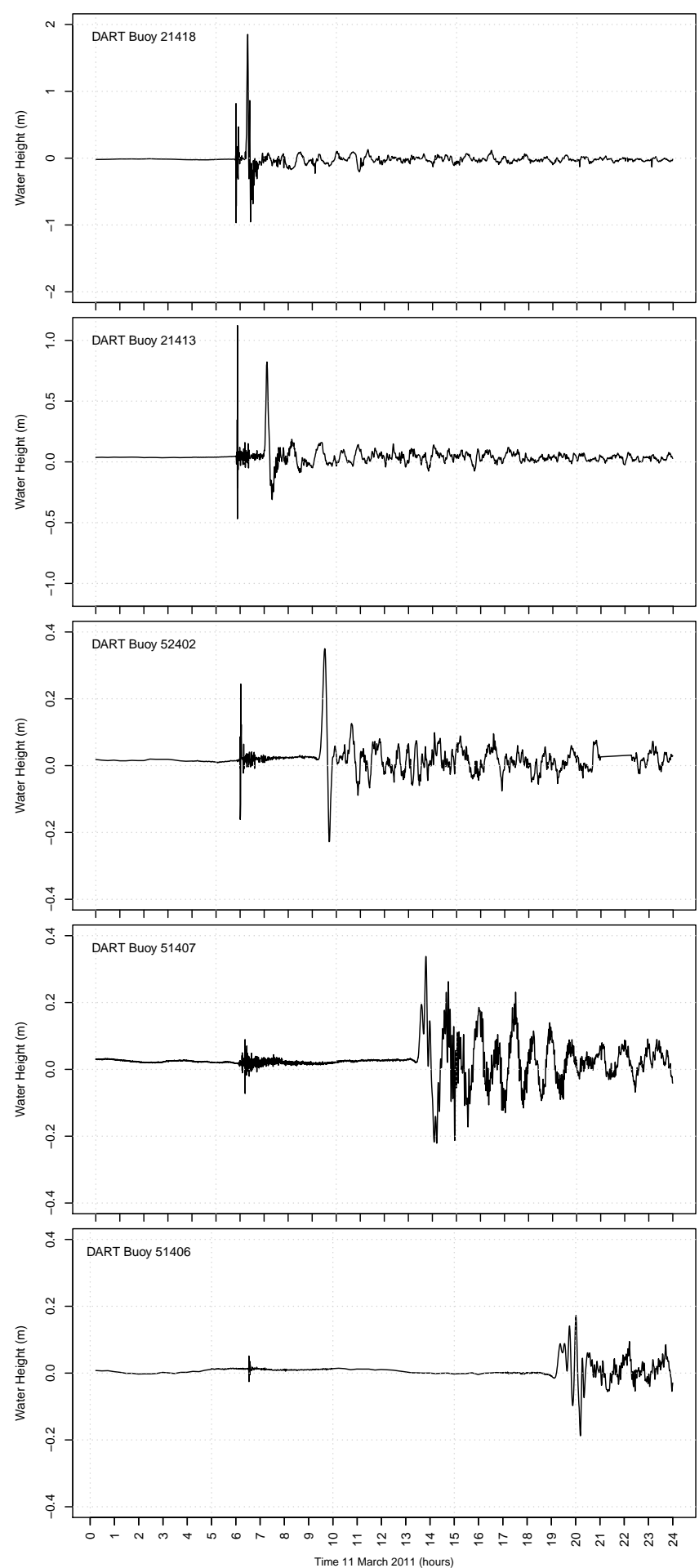

Figure 2. Wave height in meters for five DART tsunami buoys for 11 March 2011. The buoys are arranged in increasing distance from the epicenter. Data source: NOAA National Geophysical Data Center.
Table 3. Regions used in the experiments to analyze the chlorophyll increases.

\begin{tabular}{lcccc}
\hline Region & Lat. min & Lat. max & Long. min & Long. max \\
\hline R1 & 35.5 & 39.0 & 140.6 & 141.5 \\
R2 & 37.0 & 38.0 & 141.0 & 143.9 \\
\hline
\end{tabular}
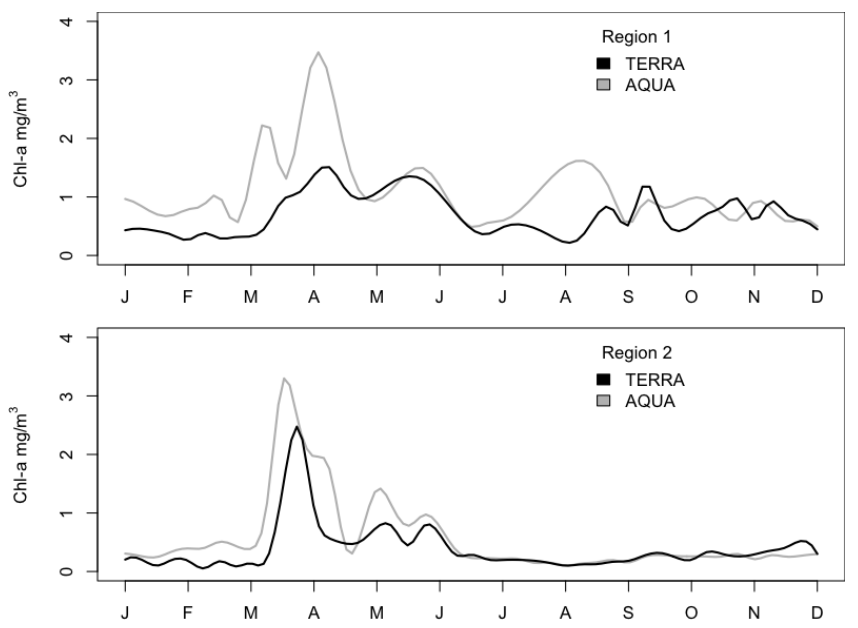

Figure 3. Average chlorophyll concentration for Region 1 and Region 2 for year 2011 retrieved by NASA MODIS onboard TERRA and AQUA. The concentrations are in a logarithmic scale.

\section{Results and discussion}

Chlorophyll concentration values were downloaded from the NASA Ocean Color website for 2011 for the 3-day and 8-day $4 \mathrm{~km}$ gridded products. All values are in $\mathrm{mg} \mathrm{m}^{-3}$. The data were analyzed and plotted using the $\mathrm{R}^{7}$ statistical project. The code is available from the authors upon request.

Two regions are defined, labeled R1 and R2, to analyze the chlorophyll increases along the eastern coast of Japan (R1) as well as in deep water (R2). Table 3 shows the coordinates for the two regions. A spatio-temporal analysis was performed by averaging the chlorophyll concentration over R1 and R2 for the entire year.

Unfortunately, especially in the immediate aftermath of the tsunami, a large cloud cover made the analysis of 3-day data impractical due to the large presence of missing pixels. Consequently, the analysis discussed in this paper is based on the weekly composite, which partially addresses the missing pixel problem by averaging values over a longer time span.

Figure 3 shows the results for R1 (top) and R2 (bottom) for both TERRA (black) and AQUA (gray). Throughout the year the largest anomalies are observed between March and April, and correspond with the occurrence of the tsunami. The maximum average concentration in $\mathrm{R} 1$ was detected using AQUA 2 weeks after the tsunami, and it corresponds

\footnotetext{
${ }^{7}$ www.r-project.org (last access: 10 July 2014)
} 


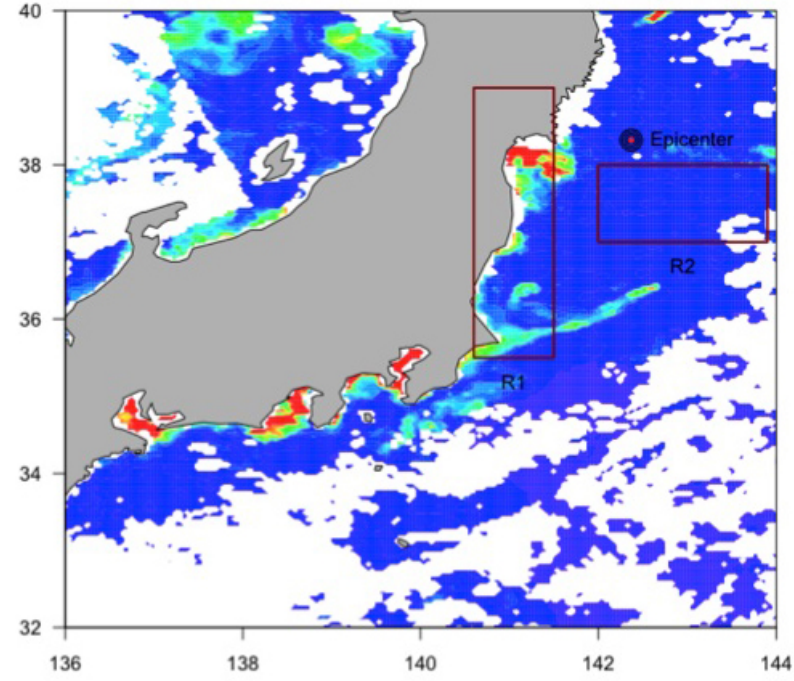

(a) AQUA Week 10

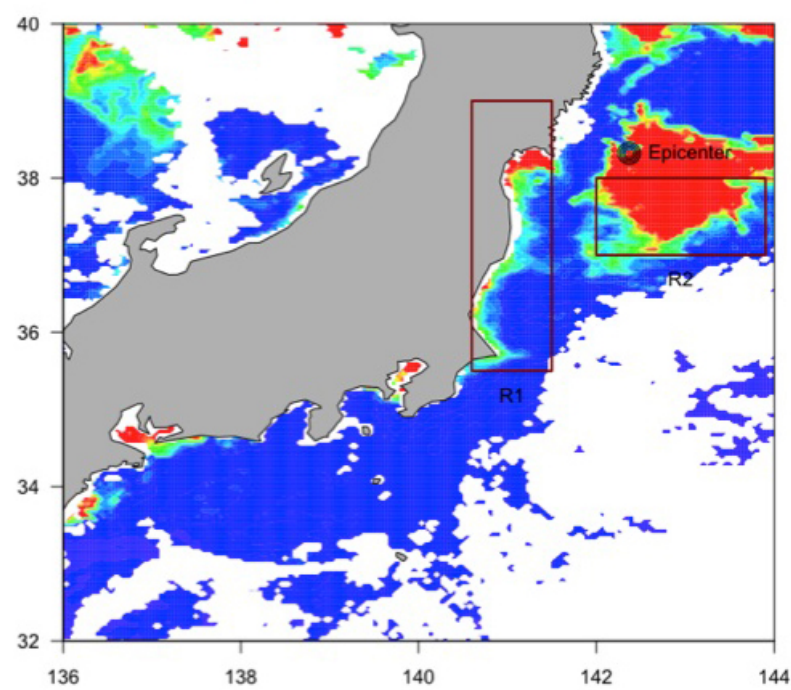

(c) AQUA Week 12

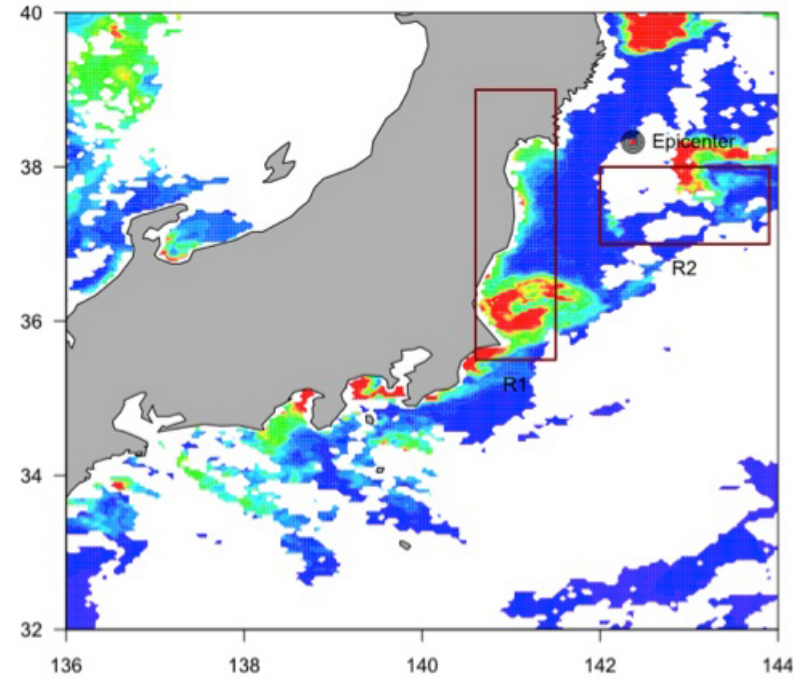

(b) AQUA Week 11

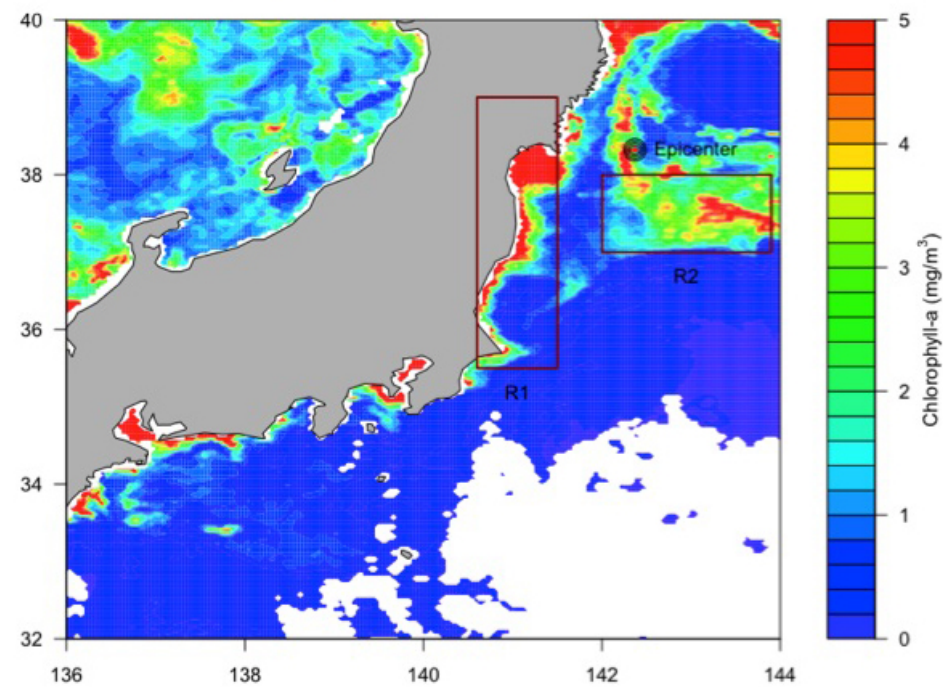

(d) AQUA Week 13

Figure 4. Chlorophyll concentration for the 4 weeks after the tsunami using AQUA. The vertical axis indicates latitude degrees north, and the horizontal axis indicates longitude degrees east.

to $3.5 \mathrm{mg} \mathrm{m}^{-3}$ against a background ranging between 0 and $1 \mathrm{mg} \mathrm{m}^{-3}$. The maximum average concentration in $\mathrm{R} 2$ was detected using AQUA the week after the tsunami, and it corresponds to $3 \mathrm{mg} \mathrm{m}^{-3}$ against a background ranging between 0 and $0.5 \mathrm{mg} \mathrm{m}^{-3}$. The values observed by AQUA are higher than for TERRA, but their temporal extents are consistent. Chlorophyll values return to the pre-tsunami level within 1 to 2 months.

Figure 4 shows the chlorophyll concentration for weeks 10 to 13 of 2011 retrieved by the MODIS instrument onboard AQUA. Week 10 corresponds to the tsunami occurrence. Large chlorophyll increases are observed over a large region, roughly centered at the epicenter, and extending west to the coast of Japan and east to buoy 21418 . Chlorophyll increases are seen both in R1 and R2, and they correspond to the largest blooming recorded during the entire year of 2011. Figure 5 shows the chlorophyll concentration for the same 4 weeks retrieved by the MODIS instrument onboard TERRA. The spatial distribution of chlorophyll concentrations between AQUA and TERRA is consistent; however, in the TERRA data the concentrations are much smaller.

The large white areas in the figures represent missing data, mainly due to cloud cover, which still remain high despite the use of the weekly composite products. In the experiments, we disregard data with less than $30 \%$ of the pixels in R1 and $\mathrm{R} 2$. This lack of data occurred sporadically throughout the 


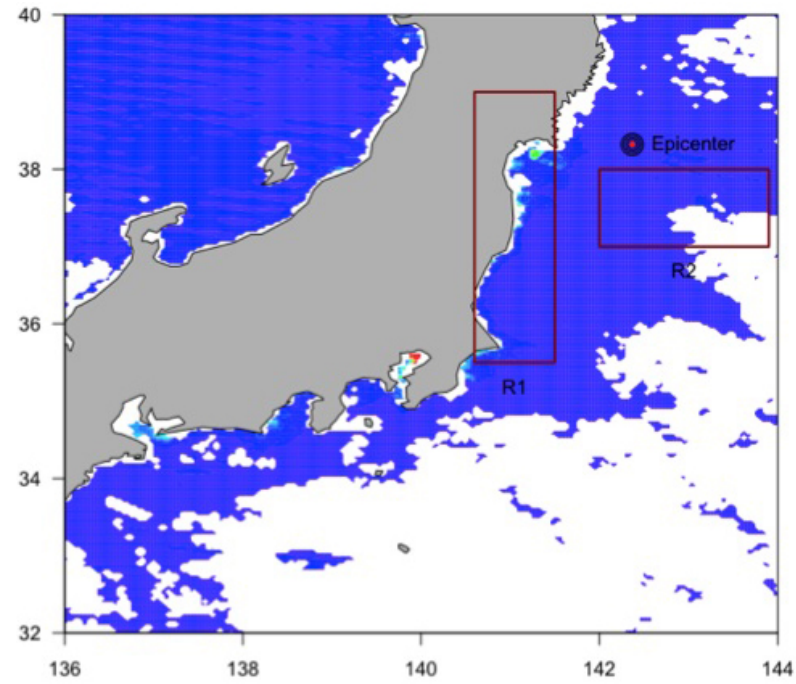

(a) TERRA Week 10

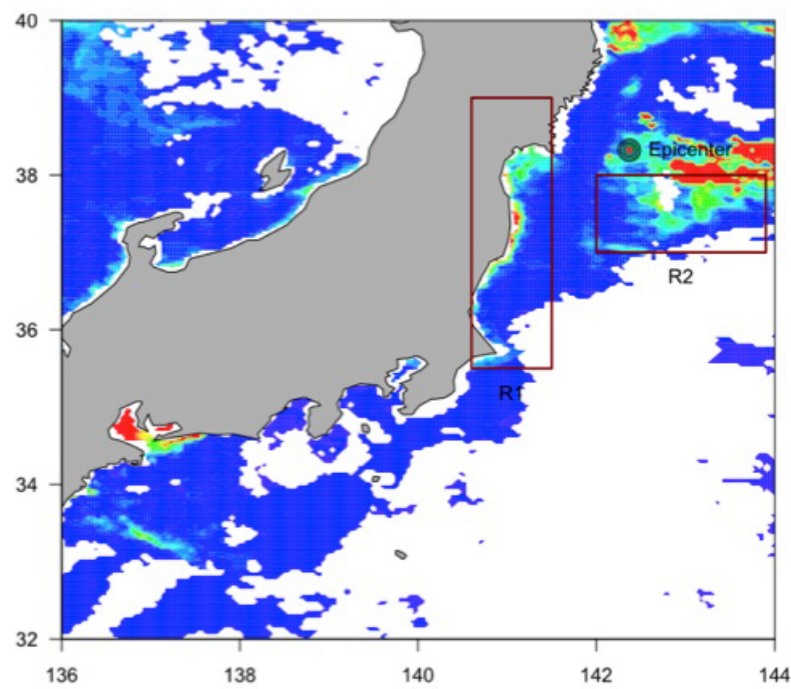

(c) TERRA Week 12

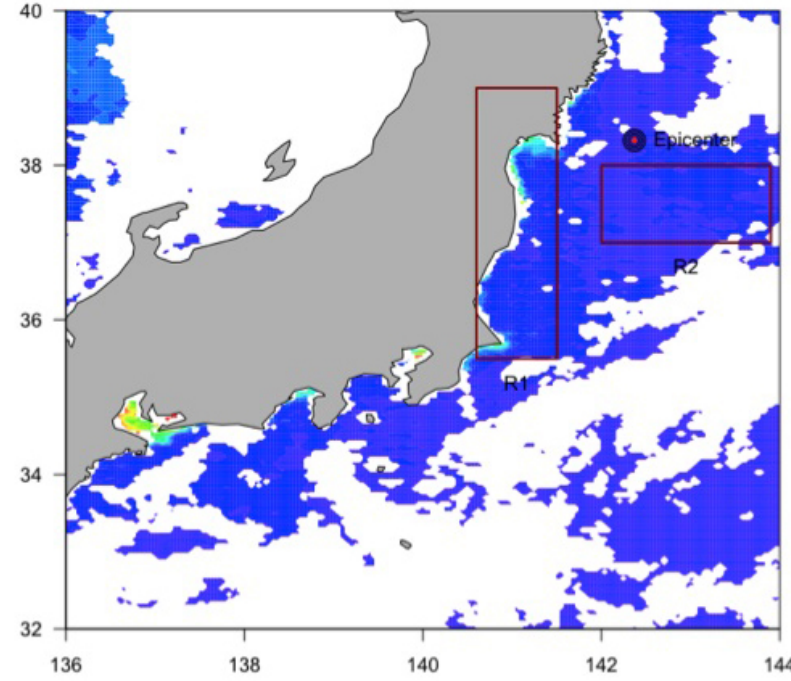

(b) TERRA Week 11

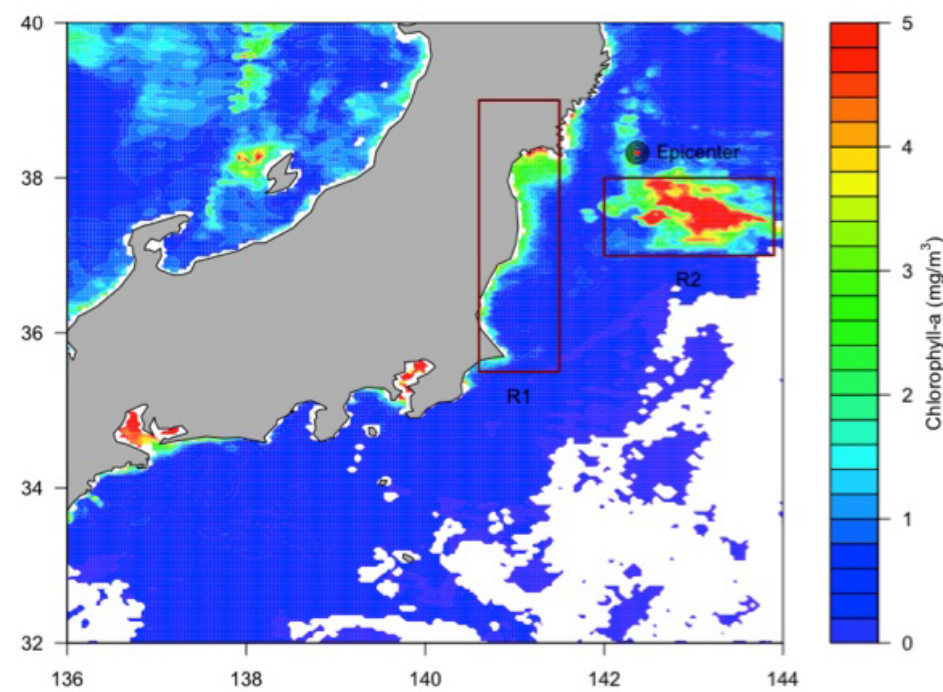

(d) TERRA Week 13

Figure 5. Chlorophyll concentrations for the 4 weeks after the tsunami using TERRA. The vertical axis indicates latitude degrees north, and the horizontal axis indicates longitude degrees east.

year, especially during the summer months where an increase cloud cover is present.

Because the MODIS instruments onboard AQUA and TERRA are the same, the lesser concentrations are due to the satellites' orbit. AQUA is specifically designed to study the earth's hydrosphere, and thus is better suited to observe concentrations in the water. Despite the lower concentrations, TERRA data are very useful to study the spatial extent of the anomalies.

Figure 6 shows the average chlorophyll concentration for 4 weeks $(6,7,8,9)$ before (left) and 4 weeks $(10,11,12$, 13) after (right) the tsunami for AQUA (top) and TERRA (bottom). The concentrations observed by AQUA are about three times higher than for TERRA, although their spatial distribution is consistent both for R1 and R2.

\section{Conclusions}

This paper discusses chlorophyll increases associated with the 2011 Japanese tsunami using remote sensing data from NASA MODIS onboard the TERRA and AQUA satellites. Large chlorophyll concentrations are observed both along the coast and in deep water, and peak between 1 and 4 weeks after the tsunami. These concentrations remained high for up to 2 months in the shallow waters along the eastern coast of Japan. 


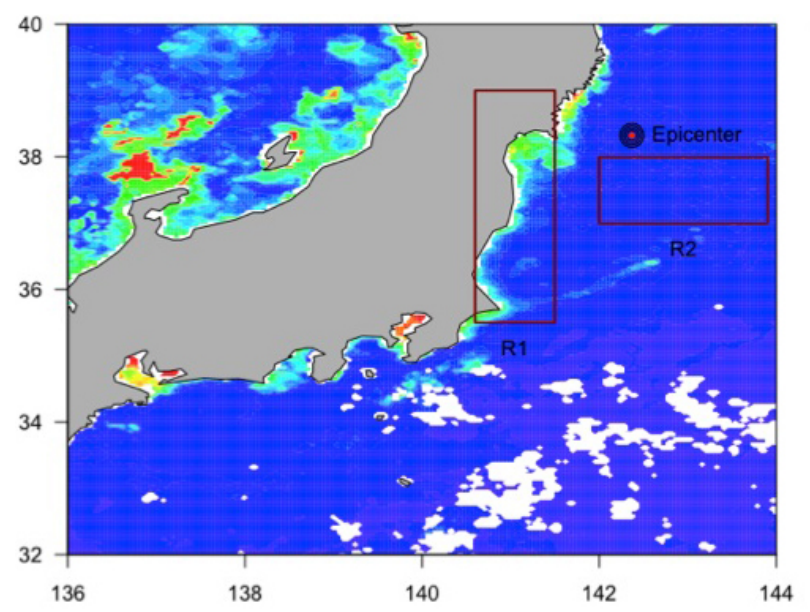

(a) AQUA Weeks $6,7,8,9$

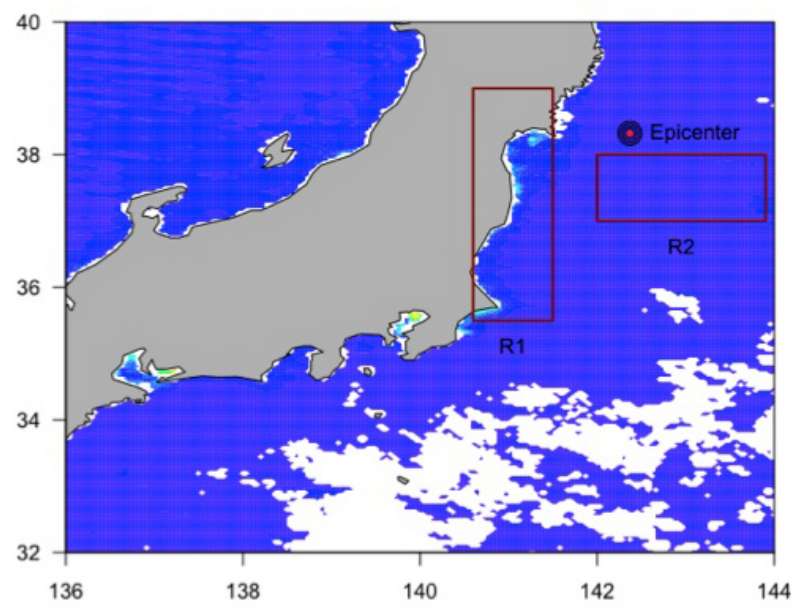

(c) TERRA Weeks $6,7,8,9$

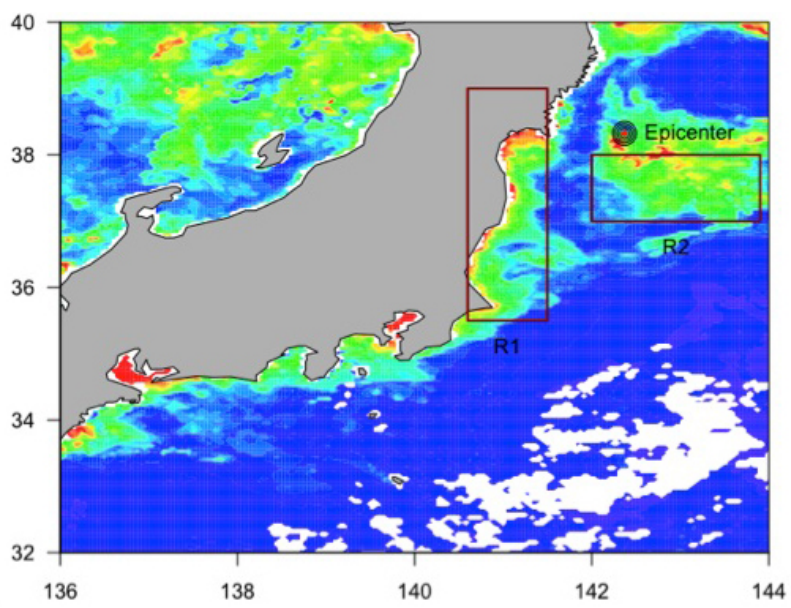

(b) AQUA Weeks 10,11,12,13

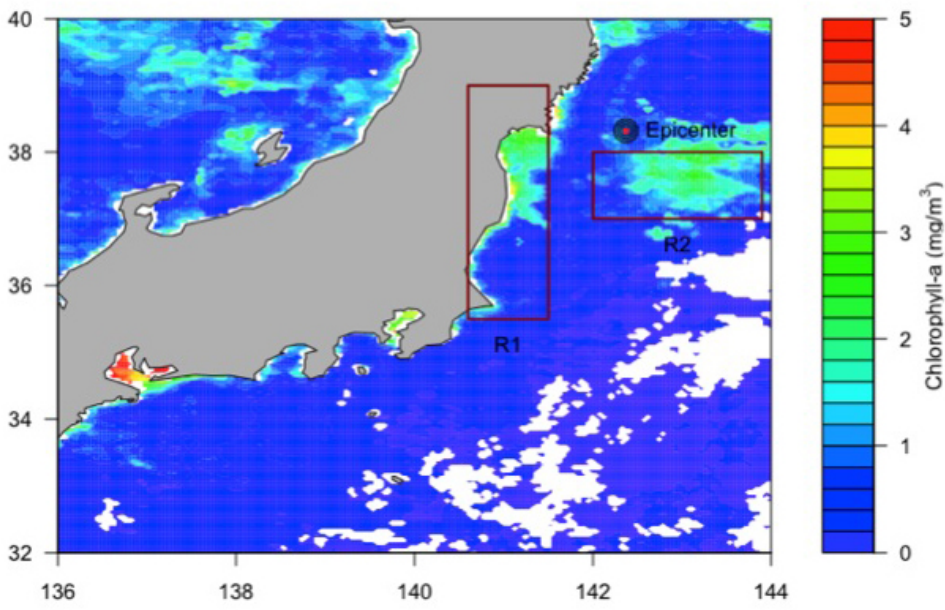

(d) TERRA Weeks 10,11,12,13

Figure 6. Average chlorophyll concentration for 4 weeks before (left) and after (right) the tsunami for AQUA (top) and TERRA (bottom). The vertical axis indicates latitude degrees north, and the horizontal axis indicates longitude degrees east.

The data from AQUA show higher concentration values than the TERRA data, but the spatial distribution of the concentrations are consistent between the two satellites. The data also illustrate how these high concentrations are concurrent with the 2011 tsunami. Therefore, the increases in chlorophyll concentrations are possibly the result from the tsunami causing unusually large upwelling of nutrients.
Acknowledgements. Work performed under this project has been partially funded by the Office of Naval Research (ONR) award \#N00014-14-1-0208 (PSU \#171570). This research was started when the first two authors were undergraduate students, and it was partially supported by the George Mason OSCAR program.

Edited by: R. Lasaponara

Reviewed by: five anonymous referees 


\section{References}

Antoine, D., d'Ortenzio, F., Hooker, S. B., Bécu, G., Gentili, B., Tailliez, D., and Scott, A. J.: Assessment of uncertainty in the ocean reflectance determined by three satellite ocean color sensors (MERIS, SeaWiFS and MODIS-A) at an offshore site in the Mediterranean Sea (BOUSSOLE project), J. Geophys. Res, 113, C07013, doi:10.1029/2007JC004472, 2008.

Bakun, A., Field, D. B., and Redondo-Rodriguez, S. J.: Greenhouse gas, upwelling-favorable winds, and the future of coastal ocean upwelling ecosystems, Glob. Change Biol., 16, 12131228, 2010.

Bezy, J., Delwart, S., and Rast, M.: MERIS-A new generation of ocean-colour sensor onboard Envisat, ESA Bull., 103, 48-56, 2000.

Boyer, J. N., Kelble, C. R., Ortner, P. B., and Rudnick, D. T.: Phytoplankton bloom status: Chlorophyll $a$ biomass as an indicator of water quality condition in the southern estuaries of Florida, USA, Ecol. Indic., 9, S56-S67, 2009.

Campbell, J. W. and Feng, H.: The empirical chlorophyll algorithm for MODIS: Testing the OC3M algorithm using NOMAD data, in: Ocean Color Bio-optical Algorithm Mini-workshop, 27-29 September 2005, 1-9, New England Center, University of New Hampshire Durham, NH, 2005.

Cannizzaro, J. P. and Carder, K. L.: Estimating chlorophyll $a$ concentrations from remote-sensing reflectance in optically shallow waters, Remote Sens. Environ., 101, 13-24, 2006.

Carder, K., Chen, F., Cannizzaro, J., Campbell, J., and Mitchell, B.: Performance of the MODIS semi-analytical ocean color algorithm for chlorophyll-a, Adv. Space Res., 33, 1152-1159, 2004.

Cervone, G. and Manca, G.: Damage Assessment of the 2011 Japanese Tsunami Using High-Resolution Satellite Data, Cartographica: The International Journal for Geographic Information and Geovisualization, 46, 200-203, 2011.

Cullen, J. J.: The deep chlorophyll maximum: comparing vertical profiles of chlorophyll a, Can. J. Fish. Aquat. Sci., 39, 791-803, 1982.

Dall'Olmo, G., Gitelson, A. A., Rundquist, D. C., Leavitt, B., Barrow, T., and Holz, J. C.: Assessing the potential of SeaWiFS and MODIS for estimating chlorophyll concentration in turbid productive waters using red and near-infrared bands, Remote Sens. Environ., 96, 176-187, 2005.

Datt, B.: Remote Sensing of Chlorophyll $a$, Chlorophyll $b$, Chlorophyll $a+$ Chlorophyll $b$, and Total Carotenoid Content in Eucalyptus Leaves, Remote Sens. Environ., 66, 111-121, 1998.

Esaias, W. E., Abbott, M. R., Barton, I., Brown, O. B., Campbell, J. W., Carder, K. L., Clark, D. K., Evans, R. H., Hoge, F. E., Gordon, H. R., Balch, W. M., Letelier, R., and Minnett, P. J.: An overview of MODIS capabilities for ocean science observations, IEEE T. Geosci. Remote, 36, 1250-1265, 1998.

Furuya, K., Takahashi, K., and Iizumi, H.: Wind-dependent formation of phytoplankton spring bloom in Otsuchi Bay in Sanriku, Japan, J. Oceanogr., 49, 459-475, 1993.

Gautam, R., Cervone, G., Singh, R., and Kafatos, M.: Characteristics of meteorological parameters associated with Hurricane Isabel, Geophys. Res. Lett., 32, L04801, doi:10.1029/2004GL021559, 2005.

Huot, Y., Brown, C. A., and Cullen, J. J.: New algorithms for MODIS sun-induced chlorophyll fluorescence and a comparison with present data products, Limnol. Oceanogr.-Methods, 3, 108130, 2005.

Kasai, H., Saito, H., Yoshimori, A., and Taguchi, S.: Variability in timing and magnitude of spring bloom in the Oyashio region, the western subarctic Pacific off Hokkaido, Japan, Fish. Oceanogr., 6, 118-129, 1997.

Kirk, J. T. O.: Light and photosynthesis in aquatic ecosystems, Cambridge University Press, 1983.

Kiyofuji, H., Hokimoto, T., and Saitoh, S.-I.: Predicting the spatiotemporal chlorophyll-a distribution in the Sea of Japan based on SeaWiFS ocean color satellite data, IEEE T. Geosci. Remote, 3, 212-216, 2006.

Letelier, R. M. and Abbott, M. R.: An analysis of chlorophyll fluorescence algorithms for the Moderate Resolution Imaging Spectrometer (MODIS), Remote Sens. Environ., 58, 215-223, 1996.

Miller, R. L. and McKee, B. A.: Using MODIS Terra $250 \mathrm{~m} \mathrm{im-}$ agery to map concentrations of total suspended matter in coastal waters, Remote Sens. Environ., 93, 259-266, 2004.

Nakagawara, E., Sakuraba, Y., Yamasato, A., Tanaka, R., and Tanaka, A.: Clp protease controls chlorophyll b synthesis by regulating the level of chlorophyllide a oxygenase, Plant J., 49, 800809, 2007.

Neville, R. and Gower, J.: Passive remote sensing of phytoplankton via chlorophyll $\alpha$ fluorescence, J. Geophys. Res., 82, 3487-3493, 1977.

O'Reilly, J. E., Maritorena, S., Mitchell, B. G., Siegel, D. A., Carder, K. L., Garver, S. A., Kahru, M., and McClain, C.: Ocean color chlorophyll algorithms for SeaWiFS, J. Geophys. Res.Oceans, 103, 24937, doi:10.1029/98JC02160, 1998.

O’Reilly, J. E., Maritorena, S., Siegel, D. A., O’Brien, M. C., Toole, D., Mitchell, B. G., Kahru, M., Chavez, F. P., Strutton, P., Cota G. F., Hooker, S.B., McClain, C., Carder, K., Muller-Karger, F., Harding, L., Magnuson, A., Phinney, D., Moore, G., Aiken, J., Arrigo, K. R., Letelier, R. M., and Culver, M.: Ocean color chlorophyll a algorithms for SeaWiFS, OC2, and OC4: Version 4, SeaWiFS postlaunch calibration and validation analyses, Part, 3, 9-23, 2000

Prakash, S. and Ramesh, R.: Is the Arabian Sea getting more productive?, Curr. Sci., 92, 667-670, 2007.

Radiarta, I. N. and Saitoh, S.-I.: Satellite-derived measurements of spatial and temporal chlorophyll-a variability in Funka Bay, southwestern Hokkaido, Japan, Estuar. Coast. Shelf Sci., 79, 400-408, 2008.

Rykaczewski, R. R. and Checkley, D. M.: Influence of ocean winds on the pelagic ecosystem in upwelling regions, P. Natl. Acad. Sci., 105, 1965-1970, 2008.

Saito, H., Kasai, H., Kashiwai, M., Kawasaki, Y., Kono, T., Taguchi, S., and Tsuda, A.: General description of seasonal variations in nutrients, chlorophyll-a, and netplankton biomass along the A-line transect, western subarctic Pacific, from 1990 to 1994, Bulletin of the Hokkaido National Fisheries Research Institute, 1998.

Sarangi, R.: Remote Sensing of Chlorophyll and Sea Surface Temperature in Indian Water with Impact of 2004 Sumatra Tsunami, Mar. Geod., 34, 152-166, 2011.

Sarangi, R. K.: Impact assessment of the Japanese tsunami on ocean-surface chlorophyll concentration using MODIS-Aqua data, J. Appl. Remote Sens., 6, 063539, doi:10.1117/1.JRS.6.063539, 2012. 
Sathyendranath, S., Prieur, L., and Morel, A.: A three-component model of ocean colour and its application to remote sensing of phytoplankton pigments in coastal waters, Int. J. Remote Sens., 10, 1373-1394, 1989.

Singh, R., Cervone, G., Kafatos, M., Prasad, A., Sahoo, A., Sun, D., Tang, D., and Yang, R.: Multi-sensor studies of the Sumatra earthquake and tsunami of 26 December 2004, Int. J. Remote Sens., 28, 2885-2896, 2007.

Siswanto, E. and Hashim, M.: A data fusion study on the impacts of the 2011 Japan tsunami on the marine environment of Sendai Bay, Int. J. Image Data Fus., 3, 191-198, 2012.

Small, L. F. and Menzies, D. W.: Patterns of primary productivity and biomass in a coastal upwelling region, Deep-Sea Res., 28, 123-149, 1981.

Son, S., Platt, T., Bouman, H., Lee, D., and Sathyendranath, S.: Satellite observation of chlorophyll and nutrients increase induced by Typhoon Megi in the Japan/East Sea, Geophys. Res. Lett., 33, L05607, doi:10.1029/2005GL025065, 2006.

Sverdrup, H. U.: On the process of upwelling, J. Mar. Res., 1, 155$164,1938$.
Takeoka, H., Kaneda, A., and Anami, H.: Tidal fronts induced by horizontal contrast of vertical mixing efficiency, J. Oceanogr., 53, 563-570, 1997.

Tan, C., Ishizaka, J., Manda, A., Siswanto, E., and Tripathy, S.: Assessing post-tsunami effects on ocean colour at eastern Indian Ocean using MODIS Aqua satellite, Int. J. Remote Sens., 28, 3055-3069, 2007.

Tanaka, A., Ito, H., Tanaka, R., Tanaka, N. K., Yoshida, K., and Okada, K.: Chlorophyll a oxygenase (CAO) is involved in chlorophyll b formation from chlorophyll a, P. Natl. Acad. Sci., 95, 12719-12723, 1998.

Walker, N. D., Leben, R. R., and Balasubramanian, S.: Hurricaneforced upwelling and chlorophyll-a enhancement within coldcore cyclones in the Gulf of Mexico, Geophys. Res. Lett., 32, L18610, doi:10.1029/2005GL023716, 2005.

Yamada, K., Ishizaka, J., Yoo, S., Kim, H.-c., and Chiba, S.: Seasonal and interannual variability of sea surface chlorophyll concentration in the Japan/East Sea (JES), Progr. Oceanogr., 61, 193-211, 2004. 